\title{
CFD ANALYSIS OF THE 24-INCH JIRAD HYBRID ROCKET MOTOR
}

\author{
Pak-Yan Liang, Ronald Ungewitter, Scott Claflin \\ CFD Technology Center \\ Rocketdyne Division, Rockwell International \\ Mail Code IB39, 6633 Canoga Avenue \\ Canoga Park, CA 91303
}

\begin{abstract}
A series of multispecies, multiphase CFD analyses of the 24-inch diameter joint government/industry IR\&D (JIRAD) hybrid rocket motor is described. The 24-inch JIRAD hybrid motor operates by injection of liquid oxygen (LOX) into a vaporization plenum chamber upstream of ports in the hydroxyl-terminated polybutadiene (HTPB) solid fuel. Injector spray pattern had a strong influence on combustion stability of the JIRAD motor so a CFD study was initiated to define the injector-end flow field under different oxidizer spray patterns and operating conditions. By using CFD to gain a clear picture of the flow field and temperature distribution within the JIRAD motor, it is hoped that the fundamental mechanisms of hybrid combustion instability may be identified and then suppressed by simple alterations to the oxidizer injection parameters such as injection angle and velocity.
\end{abstract}

The simulations in this study were carried out using the GALACSY (General ALgorithm for Analysis of Combustion SYstems) multiphase combustion codes. GALACSY consists of a comprehensive set of droplet dynamic submodels (atomization, evaporation, etc.) and a computationally efficient hydrocarbon chemistry package built around a robust Navier-Stokes solver optimized for low Mach number flows. Lagrangian tracking of dispersed particles describes a closely coupled spray phase.

The CFD cases described in this paper represent various levels of simplification of the problem. They include: $(A)$ gaseous oxygen with noncombusting fuel vapor blowing off the walls at various oxidizer injection angles and velocities, (B) gaseous oxygen with combusting fuel vapor blowing off the walls, and (C) liquid oxygen with combusting fuel vapor blowing off the walls. The study used an axisymmetric model and the results indicate that the injector design significantly effects the flow field in the injector-end of the motor. Markedly different recirculation patterns are observed in the vaporization chamber as oxygen velocity and/or spray pattern is varied. The ability of these recirculation patterns to stabilize the diffusion flame above the surface of the solid fuel gives a plausible explanation for the experimentally determined combustion stability characteristics of the JIRAD motor, and suggests how combustion stability can be assured by modifications to the injector design. Planned future activities to the submodels which allow for additional degree of realism will be discussed. 


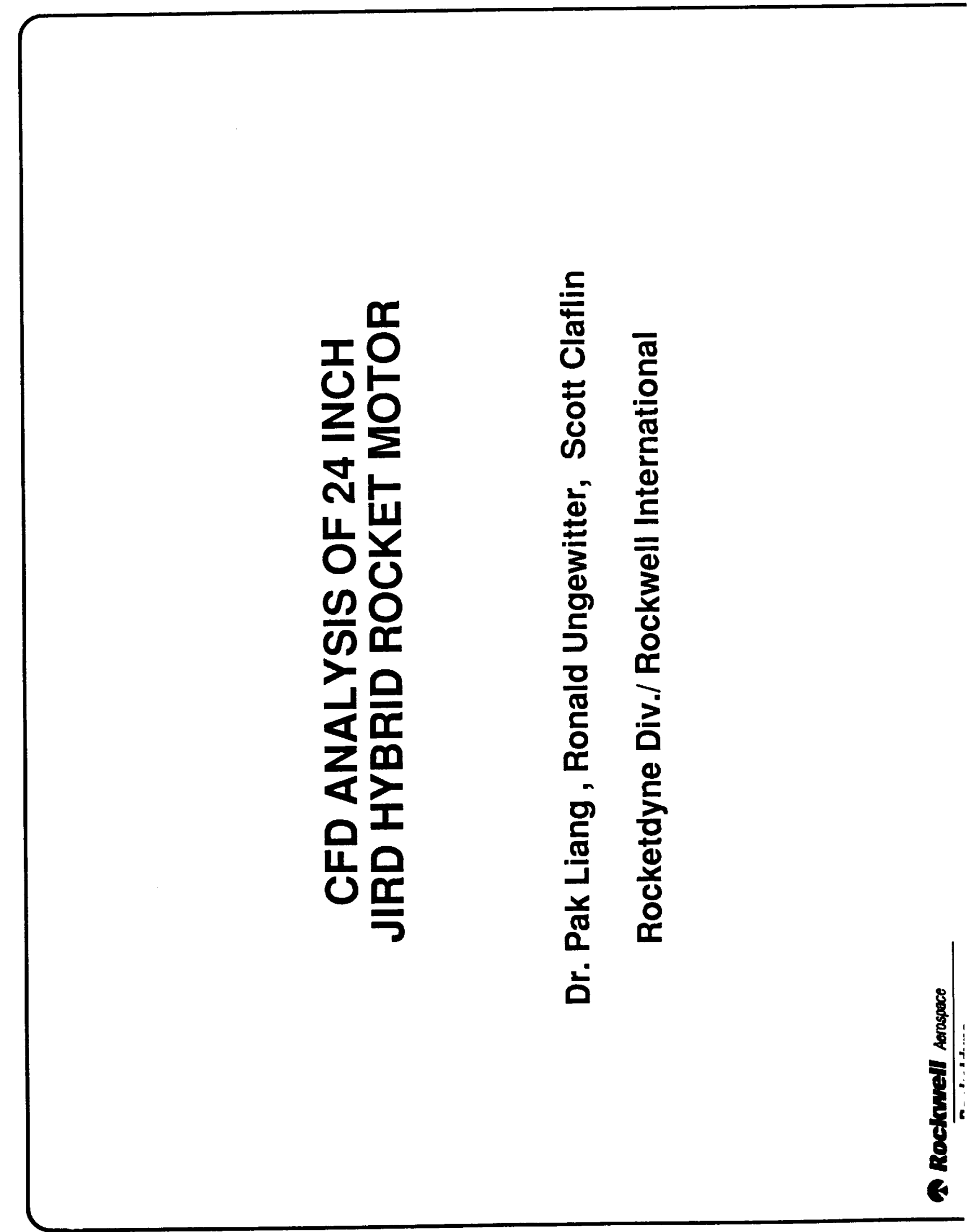



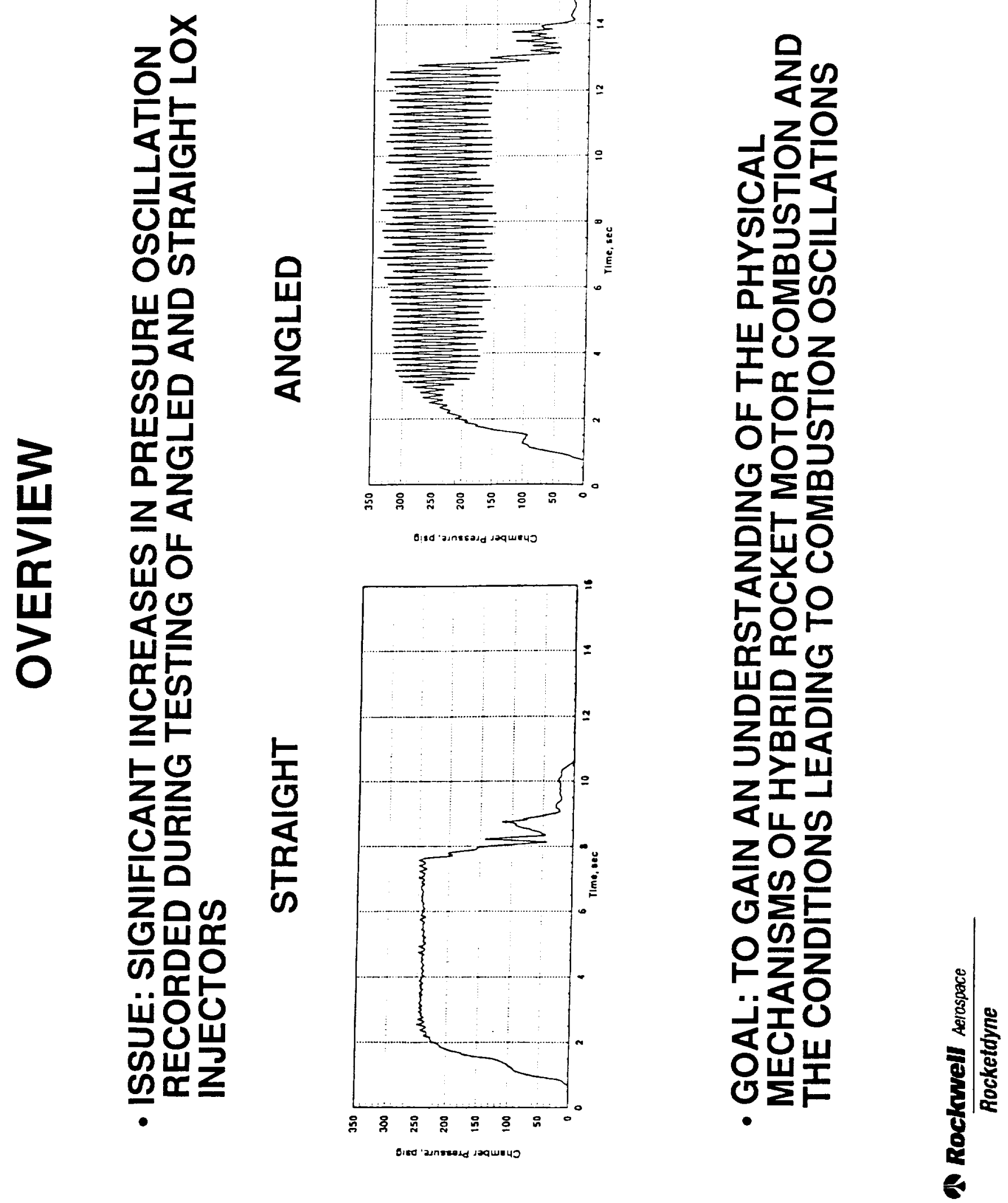


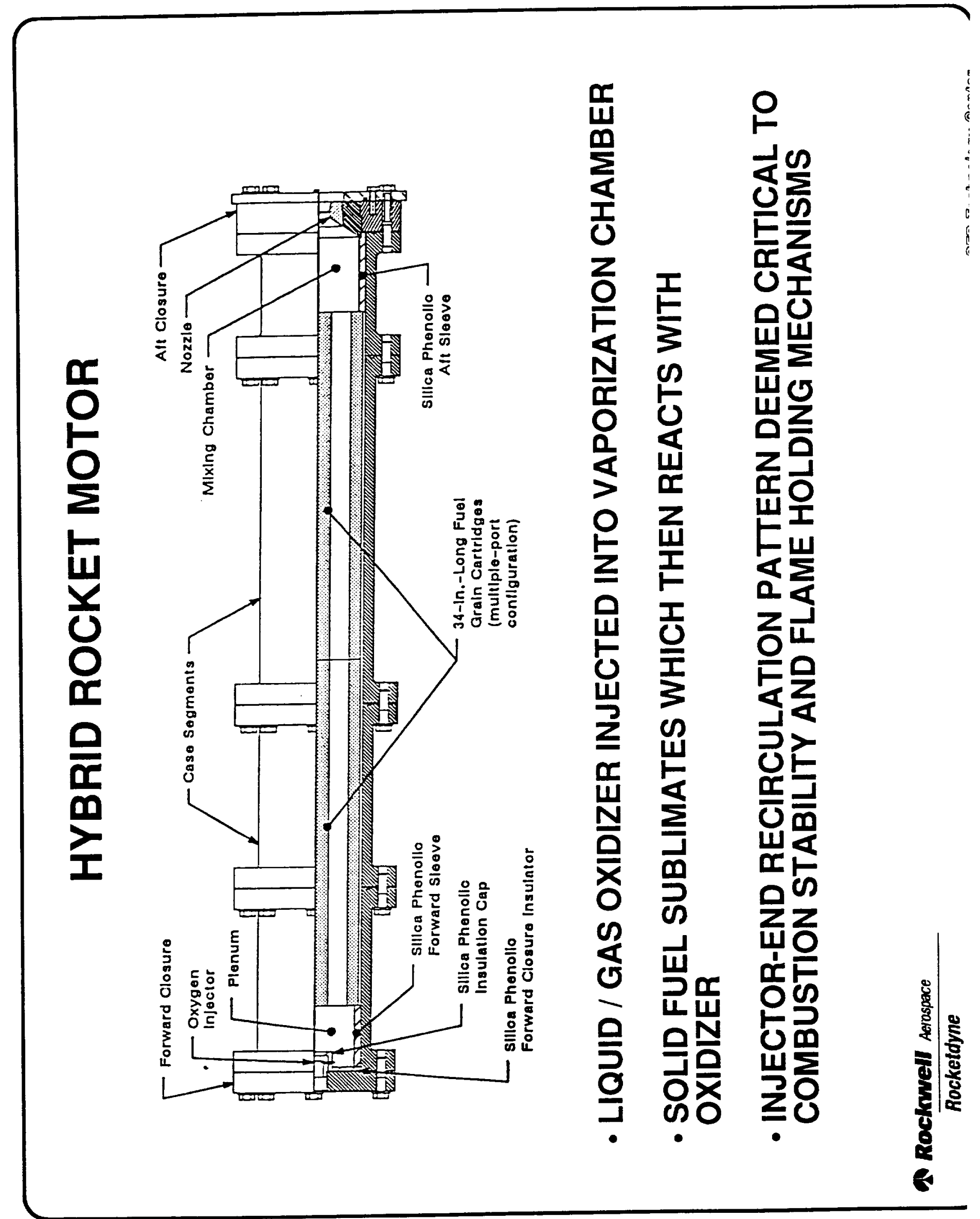




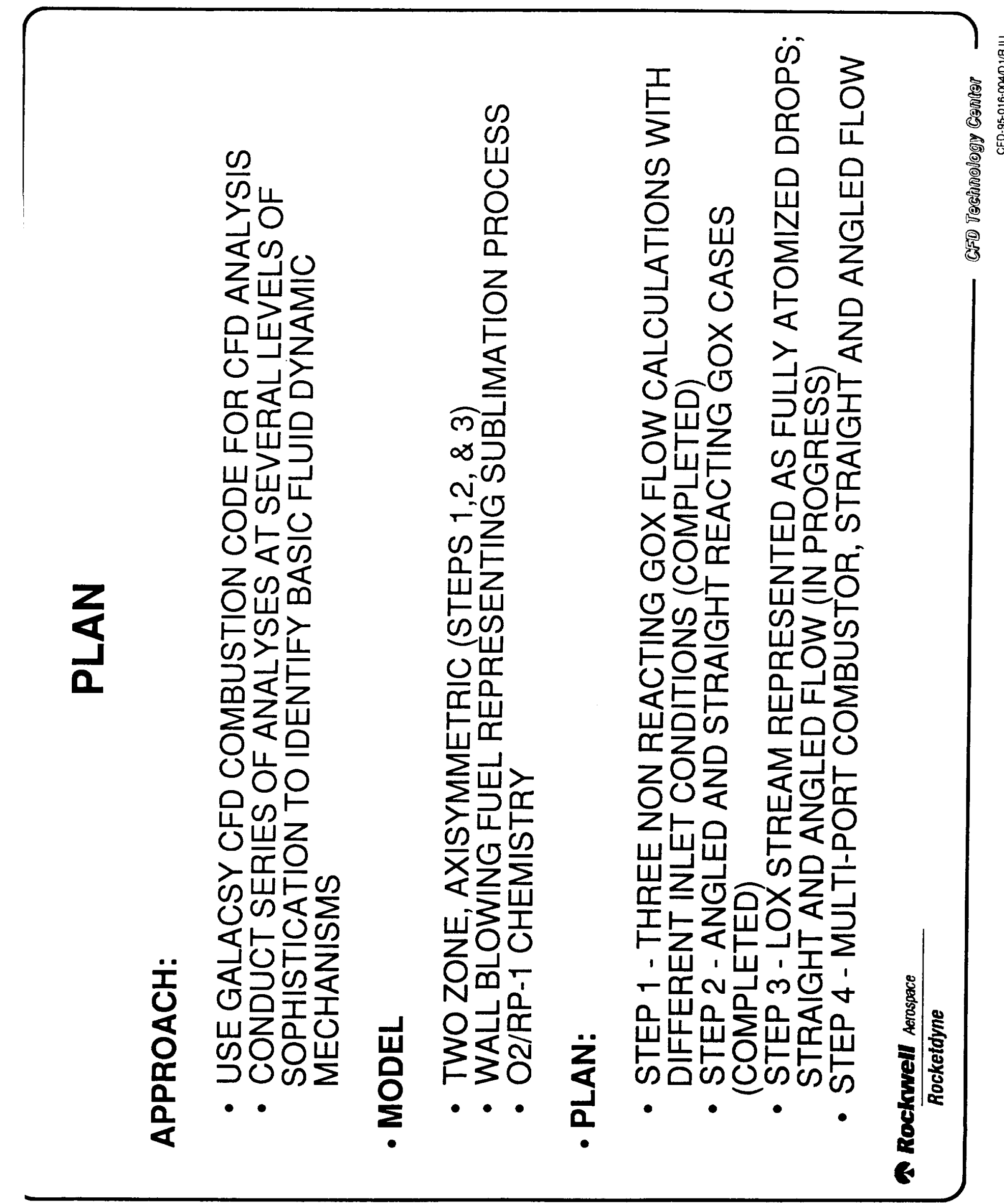




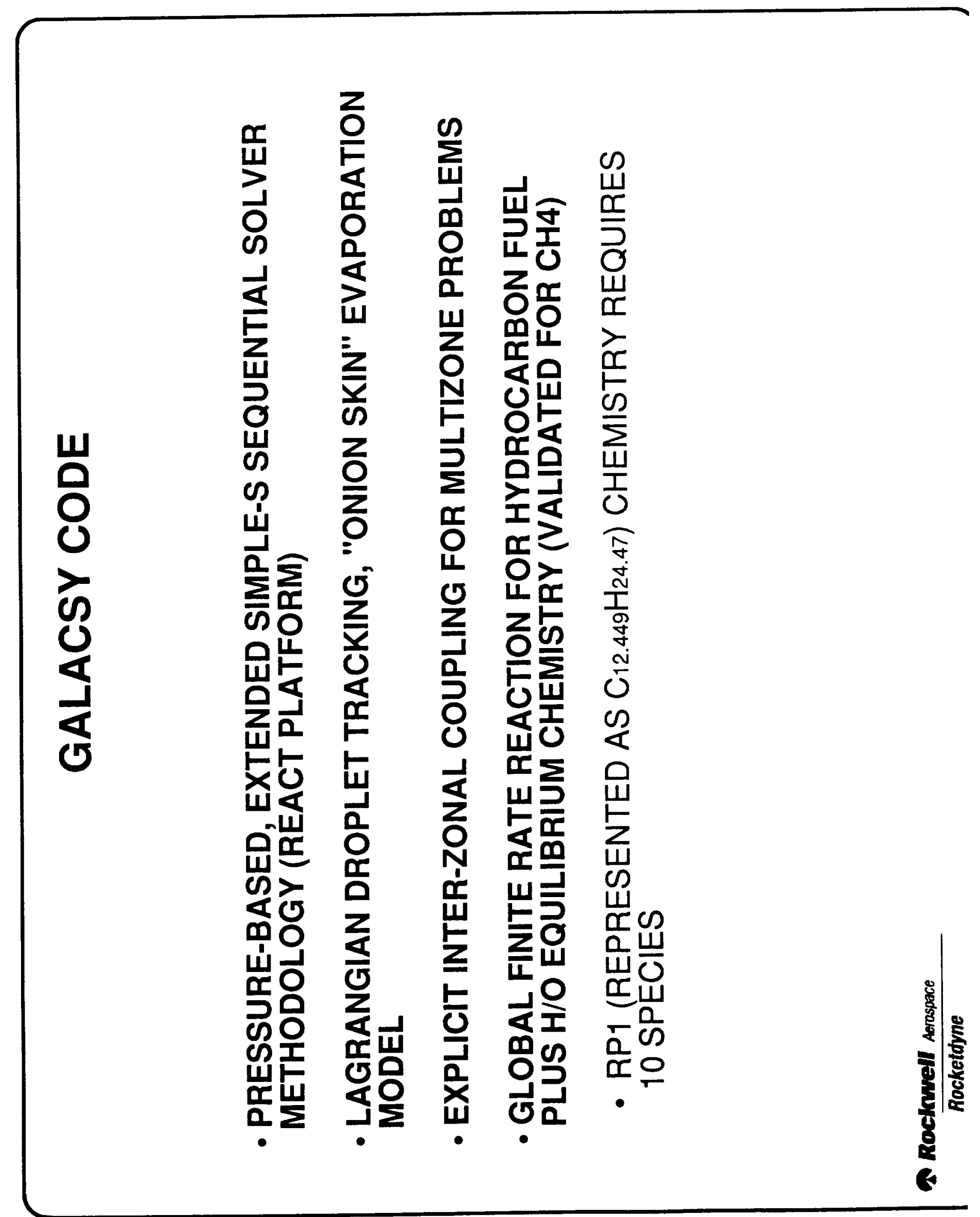



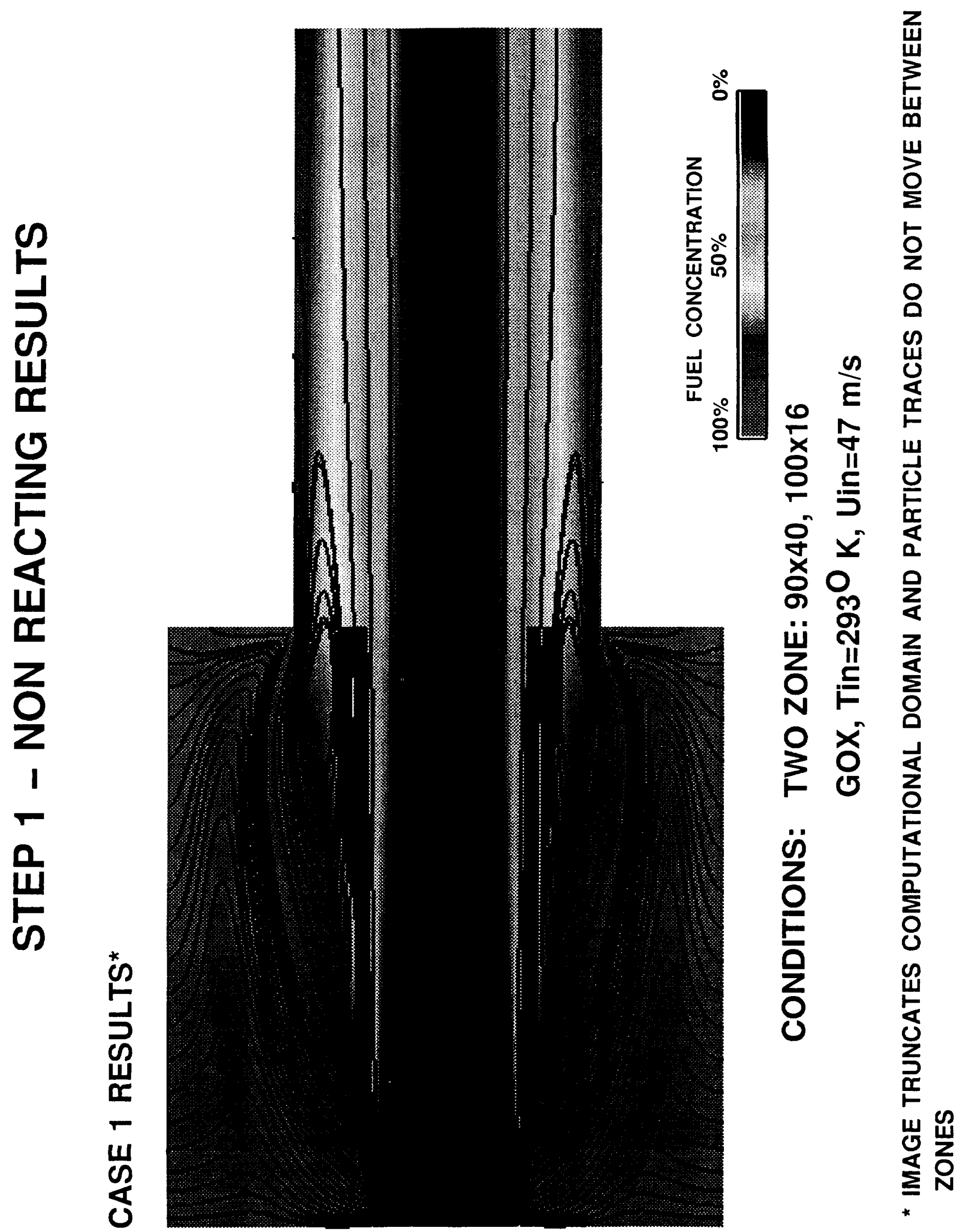


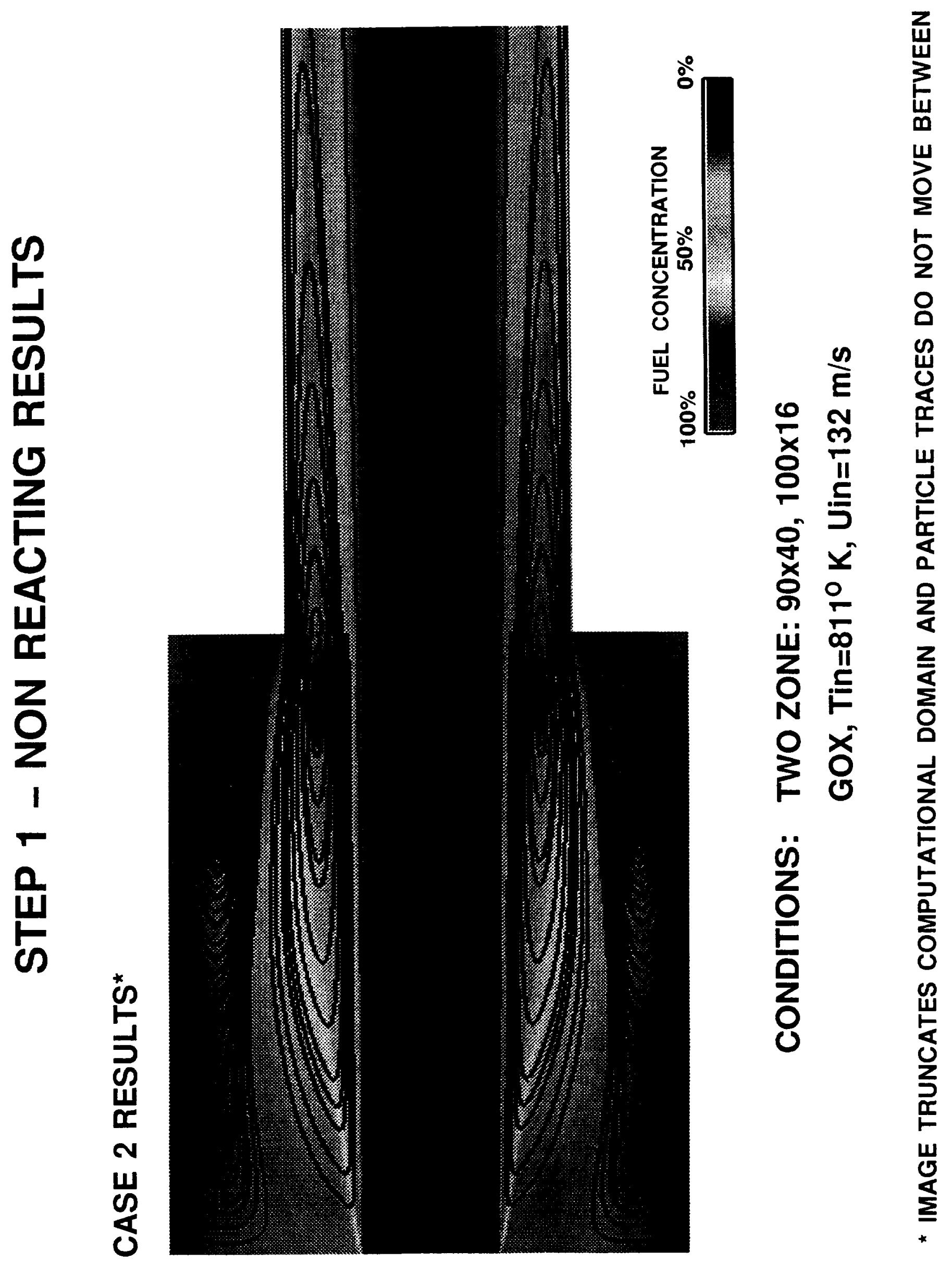




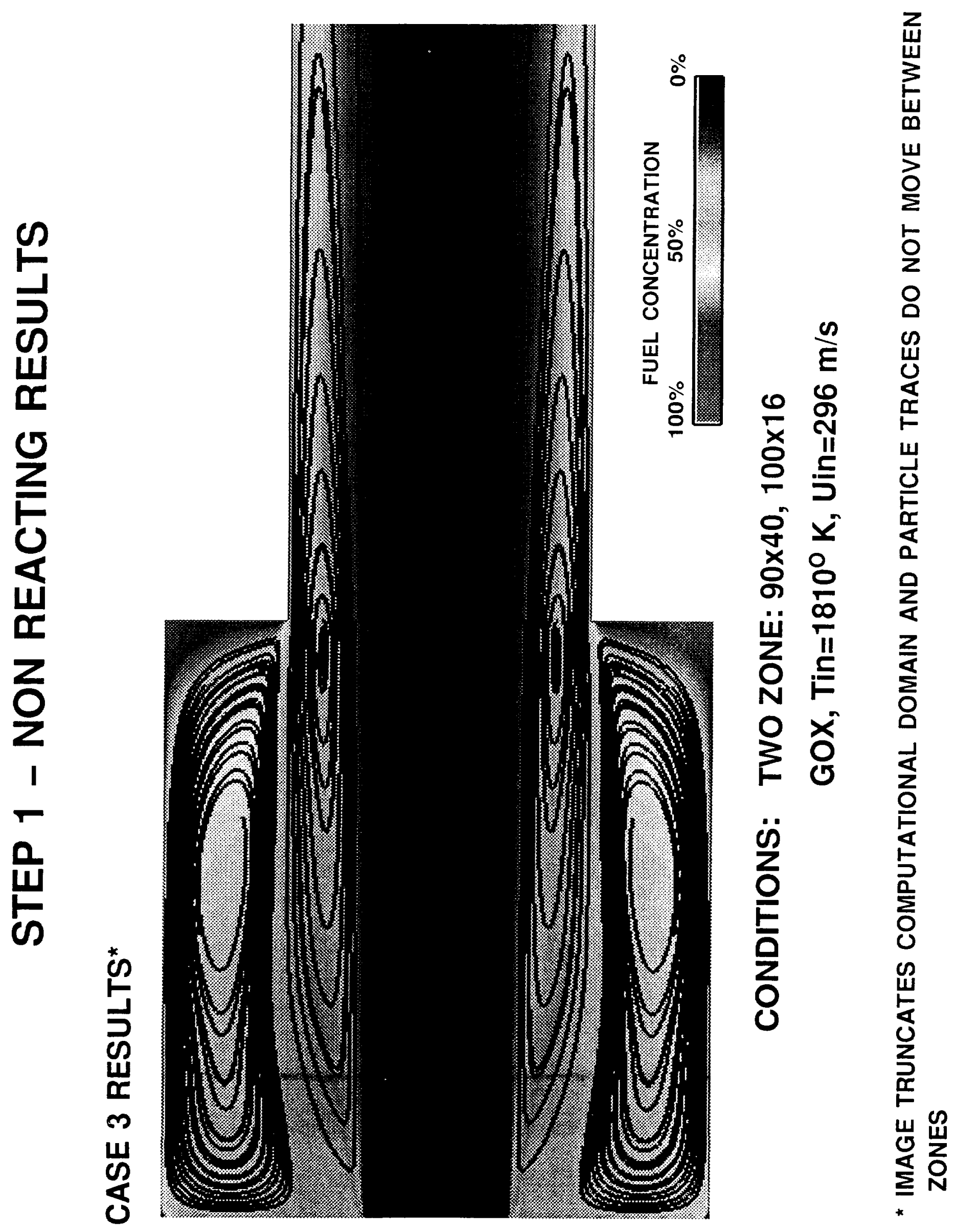




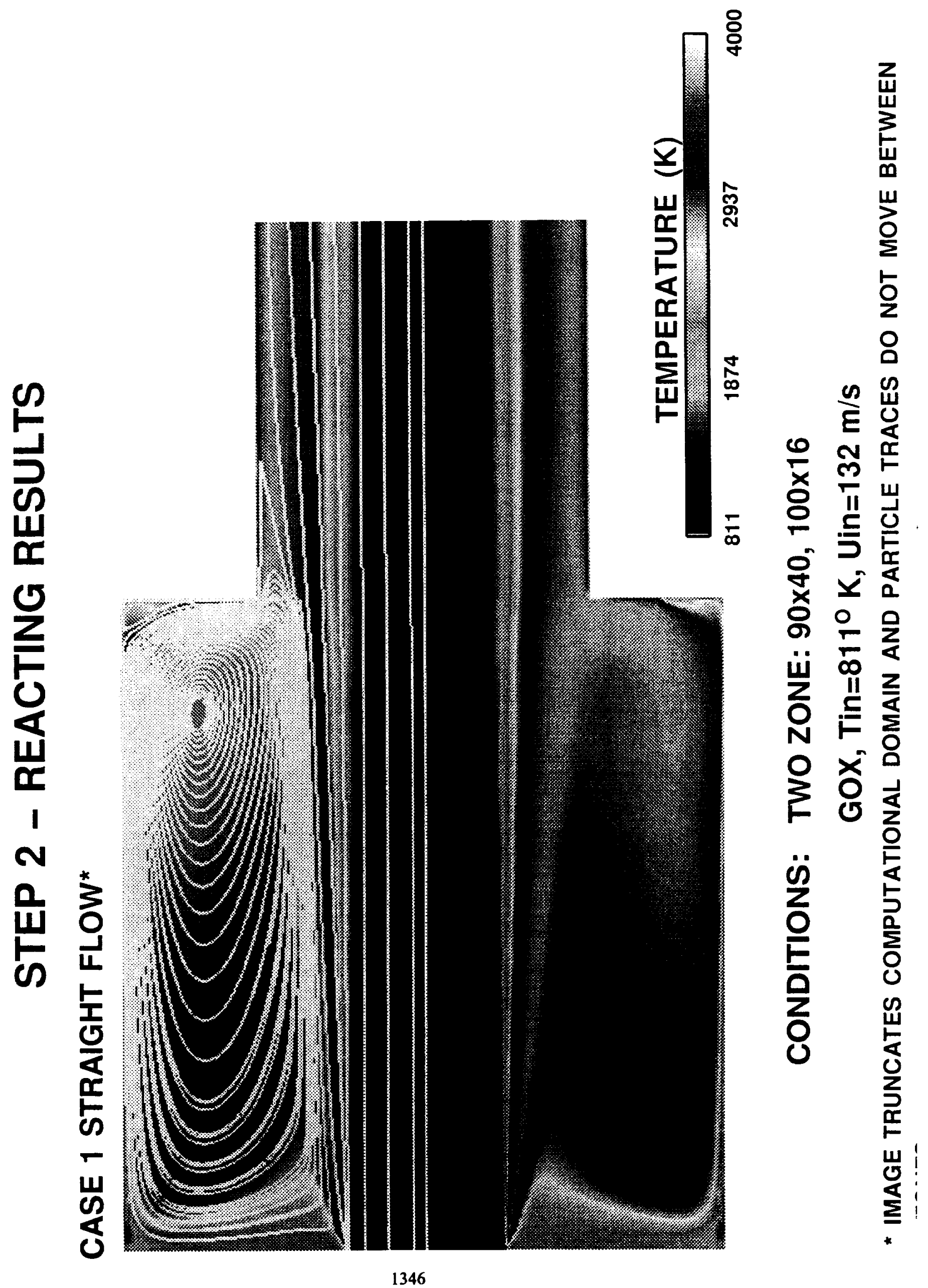








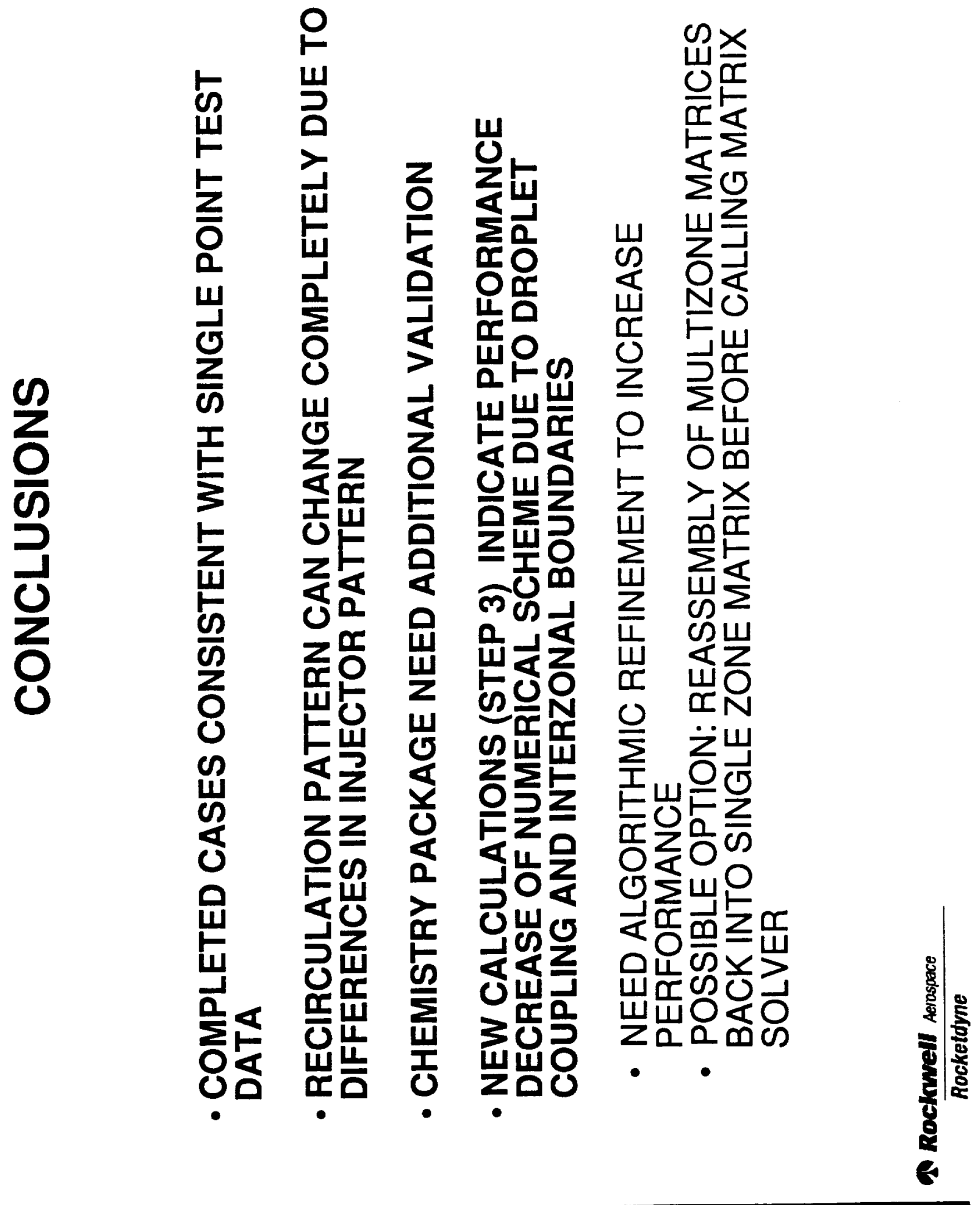



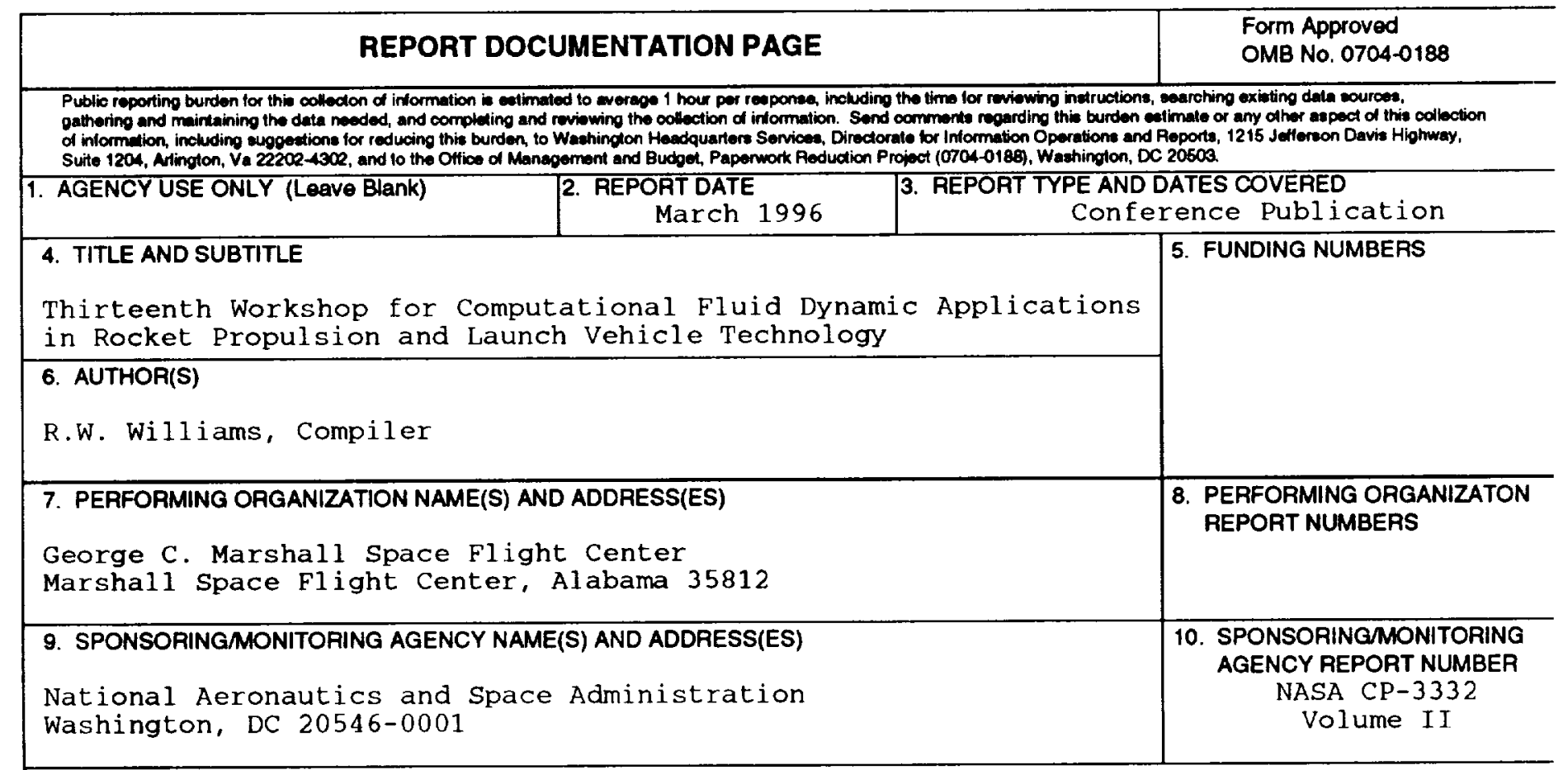

\section{SUPPLEMENTARY NOTES}

Prepared by structures and Dynamics Laboratory, Science and Engineering Directorate.

\begin{tabular}{|l|l}
\hline 12a. DISTRIBUTION/AVAILABILITY STATEMENT & 12b. DISTRIBUTION CODE
\end{tabular}

Unclassified-Unlimited

Subject Category 34

\section{ABSTRACT (Maximum 200 words)}

This conference publication includes various abstracts and presentations given at the 13 th Workshop for Computational Fluid Dynamic Applications in Rocket Propulsion and Launch Vehicle Technology held at the George C. Marshall Space F1ight Center April $25-27$ 1995. The purpose of the workshop was to discuss experimental and computational fluid dynamic activities in rocket propulsion and launch vehicles. The workshop was an open meeting for government, industry, and academia. A broad number of topics were discussed including computational fluid dynamic methodology, liquid and solid rocket propulsion, turbomachinery, combustion, heat transfer, and grid generation.

14. SUBJECT TERMS computational fluid dynamics, rocket propulsion, launch vehicle technology, liquid rocket, solid rocket, turbopump, turbomachinery, combustion, methodology, impeller, inducer, heat transfer, grid generation, nozzle, plume spray, injector \begin{tabular}{|l|l|l|} 
17. SECUAITY CLASSIFICATION & 18. SECURITY CLASSIFICATION & 19. SECURITY CLASSIFICATION
\end{tabular} Unclassified OF THIS PAGE Unclassified OF ABSTRACT

Unclassified
15. NUMBER OF PAGES 668

16. PRICE CODE A99

20. LIMITATION OF ABSTRACT Unlimited 

National Aeronautics and

Space Administration

Code JTT

Washington, DC

20546-0001

Official Business

Penalty for Private Use, $\$ 300$ 